\title{
Modeling Consumer Sensitivity for Product Design and Perceived Usability
}

\author{
Tareq Ahram*, Waldemar Karwowski, and Nabin Sapkota \\ Institute for Advanced Systems Engineering, \\ Department of Industrial Engineering and Management Systems \\ University of Central Florida \\ Orlando, FL 32816, USA \\ tahramaucf.edu
}

\begin{abstract}
The primary objective of this research paper is to investigate the relationship between the perceived qualities of home appliances with respect to various design features. Consumers may define their fondness of the particular system or model over other model(s) by using different sensibility words such as robust, sleek, luxurious, reliable, sturdy, comfortable etc. It is the objective of this study to determine the principal sensibility word(s) consumers use to define their perceived feelings about the particular model and investigate if these words are related to the design elements of the system and if such relationship exits, then the objective is to determine the optimal design criteria(s) so as to attain the maximum possible perceived quality of the system for which the consumer may have upon interacting with other comparable systems. This research is based on statistical regression and correlation analysis with multiple linear objective programming (MLOP) for thirteen selected sensibility words and twelve product models with respect to forty nine design elements (37 unique design elements broken down to 49 independent variables). Results provided significance using statistical modeling arrived at fuzzy set logic and MLOP.
\end{abstract}

Keywords: Consumer Sensitivity, Product Design, Perceived Usability.

\section{Introduction}

Brand sensitivity, defined as: "the extent to which consumers take the brand itself into account in the evaluation process" $[2,3,4]$, has proven to be an important variable to take into account when shaping a brand strategy. Brand sensitivity arises from functions the brand plays in the choice, and which explains $65 \%$ of the variance of brand sensitivity for data over a wide range of products [5].

These days there is a fierce competition in the appliances' market. There are many manufacturers that are trying to survive, some are trying to maintain their market share or some are trying to excel in their area in terms of total revenue or total market

\footnotetext{
* Corresponding author.
} 
share. One of the appliances experiencing this tougher competition is the market for refrigerators. Introduction of newer technology, innovative designs and quality refrigerators are common in today's market. The key issue in winning the customers' interest to buy one's product is to know how they perceive overall quality of the product upon looking at it or by interacting with it. To know what is important for the customers in terms of their perceived quality or psychological feeling about the product is vital to the design-phase as some of the perceived quality may be related directly/indirectly to one or more features of the design elements. Relationship between perceived quality by the consumers and the products' respective design elements can provide competitive edge to the manufacturers in selling their products.

It is the objective of this study to determine the principal sensibility word(s) consumers use to define their perceived feelings about the particular model of home appliance and investigate if these words are related to the design elements of the appliance and if such relationship exits, then the objective is to determine the optimal design criteria(s) so as to attain the maximum possible perceived quality of the appliance, in this study researchers selected to study refrigerators. The best refrigerator or any home appliance brands are hard to determine in that there are so many high quality manufacturers on the market today. Especially when you take into account the best brand may not have the model, color or style that you're looking for. That said, names like Kitchenaid, Samsung, LG, GE and Frigidaire might be expected to top the list.

\section{Methodology}

The methodology described in Kwon [1] was used in this study. Summary of the methodology explained provided by Kwon [1] as follows: Extracting sensibility characteristics, The degree of feeling cannot be expressed in numerical values; therefore, they are represented by trapezoidal membership function characterized by four corner points and 5 such sets represent 'very bad', 'bad', 'medium', 'good' and 'very good' status/degree of words related to human sensibility. In this phase, consumers are asked to interact with the target product and consumers are asked to describe their perceived quality and emotional aspect related to the product after their interaction. Words that are related with the emotional aspect and human sensibility are selected and the consumers are again asked to evaluate those words according their own feeling with regard to the target product [1]. Then only words scoring high and very high are selected for the further experiments. Words that do not precisely correspond to one of five fuzzy sets are translated using linguistic translation. Since the degree of feeling cannot be expressed in numerical values, they are represented by trapezoidal membership function characterized by four corner points.

Sensibility evaluation experiment. In this phase, design elements for the target product are determined and accordingly corresponding design variables are created. 
Experiments including several target products/samples are conducted using different sets of consumers (respondents) and each sensibility words are rated using a 5-point evaluation scale where each point represents one of the five fuzzy sets. Later, each fuzzy set is transformed into representative scalar quantity using suitable method.

Statistical analysis. Multiple linear regression models are developed for each sensibility word and correlation analysis is conducted for every design variable that appears to be statistically significant in the regression model.

According to Kwon [1], modeling the relation between sensibility and design elements formulated as follows:

$$
\begin{array}{ll}
\text { Max } & W_{i} M_{i} \sum_{j=1}^{k} P_{i j} X_{i j} \\
\text { s.t. } & Y_{L} \leq \beta_{i 0}+\beta_{i 1}+\beta_{i 2}+\ldots+\beta_{i k} \leq Y_{U} \\
& X_{i L} \leq X_{i L} \leq X_{i U} \\
& a \leq g\left(X_{i j}\right) \leq b \\
& X_{i j} \geq 0 \quad \forall j \quad(j=1,2, \ldots, k)
\end{array}
$$

Where $\mathrm{Wi}$ is the relative normalized weighted value of the ith sensibility word according to the consumer, $\mathrm{Mi}$ is the normalized weight according to the coefficient of determination for the ith sensibility word, Pij is the relative normalized weighted value of the jth design element to the partial correlation coefficients and $\mathrm{Xij}$ is the jth design element corresponding significantly to the ith sensibility word. $\beta_{i 0}+\beta_{i 1}+\beta_{i 2}+\ldots+\beta_{i k}$ is the regression model for the ith sensibility word. YL and $\mathrm{YU}$ are the lower and upper boundaries of the sensibility score and $a \leq g\left(X_{i j}\right) \leq b$ is the limited equation concerning technological limitation for the design element $\mathrm{Xij}$.

\section{Assumptions:}

- Defuzzufication or changing fuzzy set into a scalar quantity is better represented in our study by the center of gravity approach rather than the median rule due to the selected numerical sets.

- Very few missing data points from participant responses were substituted by the average value for that particular product.

- Participant mean rating for the word "ordinary" is 1 as the mean rating for the opposite word "interesting" is 4.67. Maximum rating [5-4.67=0.33] would be the rating for the word ordinary. Since the mean rating cannot be less than the lowest possible value, which is 1 , hence, it was substituted with the minimum or a mean rating of 1 for the sensibility word "ordinary".

- Similarly, for the word "hard", the mean rating is 3 as the opposite word "soft" has a mean rating of 2 . 
Using the rating data collected from the study participants Design elements determined for the various refrigerators;

Data received were the responses in 1 to 5 scales:

1 for 'very little'

2 for 'little'

3 for 'neutral'

4 for 'much'

5 for 'very much

Data received from the respondents for twelve refrigerator models of side by side freezers from different manufacturers (coded as model B, C, D, F, G, H, J, K, L, M, P). Participants were asked to rate each refrigerator model according to thirteen sensibility words (pre-determined by Human Factors Team). The sensibility words chosen for the study were: 'New', 'Robust', 'Friendly', 'Elegant', 'Smooth', 'Classic', 'Flowing', 'Ordinary' 'Expensive', 'Hard', 'Reliable', 'Perfect', and 'Convenient'. The number of respondents for each model is as follows: 23 for models (B, C, D, F), 69 for G, H, J, K and 46 for models L, M, N, P. There were 7176 data points (552 x 13), out of which 6 were missing and were estimated as the mean value for that sensibility word for that refrigerator model.

Of the twelve models studied, LG, GE and Samsung refrigerators have a number of unique features depending on the model and style you choose (http://www.refrigeratorpro.com). The Profile and Monogram lines are truly innovative, but the brand itself also includes a few dynamic features. Here are a few of our design aspects that customers preferred while buying General Electric refrigerator (http://www.refrigeratorpro.com):

- Gallon Door Storage: This is a great feature for bottom freezer refrigerators. All of that valuable shelf space can be used for storage not milk.

- LED Lighting: Like Samsung and LG and GE Refrigerators. This saves on space and helps to brighten the interior of the refrigerator and doesn't give of heat.

- Durability: the product is of high quality and will stand the test of time.

- In Door Water Filters: The water filtration system implemented by GE was by far the leader in making the best quality tasting water and ice.

\section{Design Elements}

Various design elements were considered for the study and the variables representing those design elements in the subsequent analysis. For each categorical variable assuming ' $r$ ' values were represented by ' $r-1$ ' variables. For the coding of the design variables see Appendix (A)

For example, design element 'Accents' (see Table 1), can take four values was represented by X14, X15 and X16. These three are binary variables and their combined status represents the type of accents as follows: 
Table 1. Categorical variable example for design element 'Accents'

\begin{tabular}{lllll}
\hline Variables & None & Plastic & Brush & Chrome \\
\hline X14 & 0 & 1 & 0 & 0 \\
X15 & 0 & 0 & 1 & 0 \\
X16 & 0 & 0 & 0 & 1 \\
\hline
\end{tabular}

Table 2. Design Elements Coding

\begin{tabular}{|c|c|c|}
\hline Design Elements & Description & Variables \\
\hline $\begin{array}{l}\text { Ice \& Water dispenser height to width } \\
\text { ratio }\end{array}$ & Numerical & $\mathrm{X} 1$ \\
\hline Material (plastic vs. aluminum) & 1 plastic 0 Aluminum & $\mathrm{X} 2$ \\
\hline Handle length (inches) & Numerical & $\mathrm{X} 3$ \\
\hline Finish (glossy vs. matte or flat) & Matte $=0$, Glossy $=1$ & $\mathrm{X} 4$ \\
\hline Finish (smooth vs. textured) & Smooth $=0$, Textured $=1$ & $\mathrm{X} 5$ \\
\hline Ice $\&$ Water dispenser trim vs. trimless & Trimless $=0$ Trim $=1$ & $\mathrm{X} 6$ \\
\hline Hinges (hidden vs. not hidden) & Non hidden $=0$ Hidden $=1$ & $\mathrm{X} 7$ \\
\hline $\begin{array}{l}\text { Ice \& Water dispenser number of } \\
\text { paddles }(0,1,2)\end{array}$ & Numerical & $\mathrm{X} 8$ \\
\hline \multirow{3}{*}{$\begin{array}{l}\text { Categorical variable: } \\
\text { HMI technology ( touch cap vs. tactile } \\
\text { vs. membrane vs. push button) }\end{array}$} & \multirow{3}{*}{ 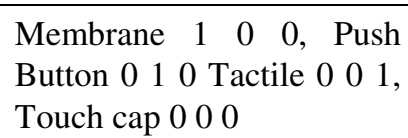 } & $\mathrm{X} 9$ \\
\hline & & $\mathrm{X} 10$ \\
\hline & & $\mathrm{X} 11$ \\
\hline \multirow{2}{*}{$\begin{array}{l}\text { Categorical variable: } \\
\text { Drip pan material (plastic vs. metal vs. } \\
\text { none) }\end{array}$} & \multirow{2}{*}{$\begin{array}{l}\text { Plastic } 10 \text {, None } 00 \text {, } \\
\text { Metal } 011\end{array}$} & $\mathrm{X} 12$ \\
\hline & & X13 \\
\hline \multirow{3}{*}{$\begin{array}{l}\text { Categorical variable: } \\
\text { Accents (plastic vs. brushed vs. chrome } \\
\text { vs. none) }\end{array}$} & \multirow{3}{*}{ 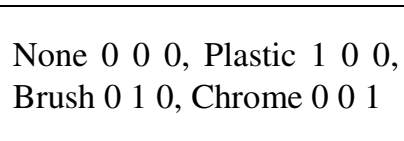 } & $\mathrm{X} 14$ \\
\hline & & $\mathrm{X} 15$ \\
\hline & & $\mathrm{X} 16$ \\
\hline Toe kick (present vs. absent) & Present 1, Absent 0 & $\mathrm{X} 17$ \\
\hline \multirow{2}{*}{ Cradle (opaque vs. clear) } & \multirow{2}{*}{$\begin{array}{l}\text { Opaque } 10 \text {, Clear } 01 \text {, Not } \\
\text { available } 00\end{array}$} & $\mathrm{X} 18$ \\
\hline & & $\mathrm{X} 19$ \\
\hline Unit Face form ( bow vs. flat) & Flat 0 , Bow 1 & $\mathrm{X} 20$ \\
\hline \multirow{2}{*}{ Cradle surface (rubberized vs. none) } & \multirow{2}{*}{$\begin{array}{l}\text { Rubberized } 10 \text {, None } 01 \text {, } \\
\text { Not available } 00\end{array}$} & $\mathrm{X} 21$ \\
\hline & & $\mathrm{X} 22$ \\
\hline \multirow{2}{*}{$\begin{array}{l}\text { Handle shape ( } \mathrm{D} \text { vs. tube vs. finger } \\
\text { dented) }\end{array}$} & \multirow{2}{*}{$\begin{array}{l}\mathrm{D} \text { shape } 00, \mathrm{FD}=0 \quad 1 \text {, } \\
\text { Tube } 10\end{array}$} & $\mathrm{X} 23$ \\
\hline & & $\mathrm{X} 24$ \\
\hline \multirow{2}{*}{$\begin{array}{l}\text { Handle style ( box vs. taper vs. truncated } \\
\text { vs. blended) }\end{array}$} & \multirow{2}{*}{$\begin{array}{l}\text { Blended }=00, \text { truncated }= \\
10, \text { tapered }=01\end{array}$} & $\mathrm{X} 25$ \\
\hline & & $\mathrm{X} 26$ \\
\hline Handle offset/gap & Numerical & $\mathrm{X} 27$ \\
\hline \multirow{2}{*}{ Gloss level } & \multirow{2}{*}{$\begin{array}{l}0 \quad 0=\text { Low } 0 \quad 1=\text { Medium } \\
\text { High } 10\end{array}$} & $\mathrm{X} 28$ \\
\hline & & $\mathrm{X} 29$ \\
\hline
\end{tabular}


Table 2. (Continued)

\begin{tabular}{|c|c|c|}
\hline Design Elements & Description & Variables \\
\hline $\begin{array}{l}\text { Dispenser recess dimensions ( } \mathrm{H} \mathrm{X} \mathrm{W} \mathrm{X} \\
\text { D) }\end{array}$ & Volume & $\mathrm{X} 30$ \\
\hline Display dimensions (H / W) & Numerical Area & $\mathrm{X} 31$ \\
\hline Size of drip pan (W / D ) & Numerical Area & $\mathrm{X} 32$ \\
\hline $\begin{array}{l}\text { Dispenser HMI material (metal vs. } \\
\text { plastic vs. glass) }\end{array}$ & Plastic $=0$, metal $=1$ & X33 \\
\hline $\begin{array}{l}\text { Button material (plastic vs. metal vs. } \\
\text { painted to look like metal) }\end{array}$ & Plastic $=0$, metal $=1$ & X34 \\
\hline Ice maker (in case vs. on the door) & In case $=0$, door $=1$ & $\mathrm{X} 35$ \\
\hline $\begin{array}{l}\text { Ice maker Clear plastic to opaque } \\
\text { material ratio }\end{array}$ & Numerical & X36 \\
\hline Bin color ( Color vs. clear) & Color $=1$, Clear $/$ Color $=0$ & $\mathrm{X} 37$ \\
\hline $\begin{array}{l}\text { Shelf ( full glides vs. roller vs. partial } \\
\text { extension vs. none) }\end{array}$ & $\begin{array}{l}\text { Partial Extension }=1 \text {, None } \\
=0\end{array}$ & X38 \\
\hline Freezer bin material ( wire vs. plastic) & Wire $=0$, Plastic $=1$ & X39 \\
\hline Shelf material ( wire vs. glass) & Wire $=0$, Glass $=1$ & $\mathrm{X} 40$ \\
\hline Bin material (mixed vs. same) & Same $=0$, Mixed $=1$ & $\mathrm{X} 41$ \\
\hline Door adjustment levels & Numerical & $\mathrm{X} 42$ \\
\hline Case adjustment levels & Numerical & $\mathrm{X} 43$ \\
\hline Bin dimensions & Numerical & $\mathrm{X} 44$ \\
\hline Light type (LED vs. incandescent) & Incandescent $=0, \mathrm{LED}=1$ & $\mathrm{X} 45$ \\
\hline Liner finish ( gloss vs. matte vs. mixed) & Matte $=0$, Gloss $=1$ & $\mathrm{X} 46$ \\
\hline Shelf material plastic to glass ratio & Numerical & $\mathrm{X} 47$ \\
\hline Total fresh food capacity (cu. ft.) & Numerical & $\mathrm{X} 48$ \\
\hline $\begin{array}{l}\text { Usable fresh food capacity (Consumer } \\
\text { Reports) }\end{array}$ & Numerical & $\mathrm{X} 49$ \\
\hline
\end{tabular}

\section{$4 \quad$ Analysis and Results}

Regression analysis was performed to reveal how each of the refrigerator models did overall as far as respondent's sensibility ratings (perception) about the each refrigerator model; this was conducted in terms of sensibility scores for each sensibility word. The basic idea of ranking refrigerator models in terms of sensibilityword-scores is based on the notion that how a particular model of refrigerator did in terms of proportion of maximum possible score for that model.

For example, a maximum possible score for each word from any respondent is 5 which stand for 'very much' and scalar value for the corresponding fuzzy set for 'very much' is 6.3667 . Therefore, maximum possible score for any word for models B, C, 
$\mathrm{D}, \mathrm{F}$ is 146.434 (23 x 6.3667), and likewise, for models $\mathrm{G}, \mathrm{H}, \mathrm{J}, \mathrm{K}$ is 439.302 (69 $\mathrm{x}$ 6.3667) and for models L, M, N, P is 292.868 (46 x 6.3667). Table 7 shows the ranking of the 12 models of refrigerators for each sensibility word. Note that, rank 1 and 12 are highlighted where (1) ranks very much and (12) ranks very low, and three sensibility words (Class, Ordinary, Expensive, and Hard) sensibility ranking has been reversed to synchronize the direction for the rest of the words (see Table 3).

Table 3. sensibility word Correlation Analysis

\begin{tabular}{|c|c|c|c|c|c|c|c|c|c|c|c|c|c|}
\hline & $\frac{\vec{b}}{\mathrm{z}}$ & $\frac{\bar{z}}{\bar{a}}$ & 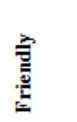 & 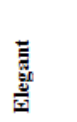 & $\frac{y}{0}$ & $\begin{array}{l}\text { 흘 } \\
\text { 竞 }\end{array}$ & है & $\frac{0}{E}$ & $\frac{0}{\frac{c}{x}}$ & $\underline{\vec{z}}$ & $\begin{array}{l}\frac{2}{3} \\
\frac{2}{2} \\
\underline{2}\end{array}$ & $\stackrel{\Xi}{0}$ & 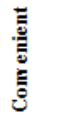 \\
\hline New & - & 0.579 & 0.348 & 0.649 & 0.412 & -0.008 & 0.450 & -0.484 & 0.625 & -0.013 & 0.328 & 0.576 & 0.393 \\
\hline Robust & 0.579 & - & 0.338 & 0.569 & 0.420 & 0.106 & 0.455 & -0.399 & 0.589 & -0.024 & 0.390 & 0.525 & 0.367 \\
\hline Classic & 0.412 & 0.420 & 0.345 & 0.502 & - & 0.077 & 0.463 & -0.322 & 0.458 & -0.083 & 0.346 & 0.446 & 0.377 \\
\hline Smooth & -0.008 & 0.106 & 0.217 & 0.163 & 0.077 & - & 0.143 & 0.204 & 0.040 & 0.070 & 0.196 & 0.142 & 0.210 \\
\hline Ordinary & 0.450 & 0.455 & 0.460 & 0.478 & 0.463 & 0.143 & - & -0.241 & 0.449 & -0.126 & 0.407 & 0.513 & 0.503 \\
\hline Flowing & -0.484 & -0.399 & -0.151 & -0.451 & -0.322 & 0.204 & -0.241 & - & -0.503 & 0.049 & -0.267 & -0.399 & -0.139 \\
\hline Expensive & 0.625 & 0.589 & 0.279 & $\underline{0.707}$ & 0.458 & 0.040 & 0.449 & -0.503 & - & -0.025 & 0.438 & 0.612 & 0.345 \\
\hline Convenient & 0.393 & 0.367 & 0.516 & 0.353 & 0.377 & 0.210 & 0.503 & -0.139 & 0.345 & -0.110 & 0.437 & 0.509 & - \\
\hline
\end{tabular}

Refrigerator design variables obtained for each sensibility word using regression and correlation analysis were optimized using MLOP as explained in the Kwon [1] and summarized below. Determine partial correlation coefficient for the variables significant in multiple linear regression models for each of the sensitivity words. Determine normalized consumer preference score for each sensibility words. Determine the normalized coefficient of determination of multiple linear regression model for each of the sensibility word. Determine the technological constraints and limitations of the variables found significant in the linear regression model for that sensibility word (provided in Table 7).

Formulate the model as follows:

$$
\begin{array}{ll}
\operatorname{Max} & W_{i} M_{i} \sum_{j=1}^{k} P_{i j} X_{i j} \\
\text { s.t. } & Y_{L} \leq \beta_{i 0}+\beta_{i 1}+\beta_{i 2}+\ldots+\beta_{i k} \leq Y_{U} \\
& X_{i L} \leq X_{i L} \leq X_{i U} \\
& a \leq g\left(X_{i j}\right) \leq b \\
& X_{i j} \geq 0 \quad \forall j \quad(j=1,2, \ldots, k)
\end{array}
$$


Table 4. Technological limitations for various design elements

\begin{tabular}{lllll}
\hline S.N. & Design Element & $\begin{array}{l}\text { Minimum } \\
\text { value }\end{array}$ & $\begin{array}{l}\text { Maximum } \\
\text { value }\end{array}$ & Variable \\
\hline $\mathbf{1}$ & $\begin{array}{l}\text { Ice \& Water dispenser height to } \\
\text { width ratio }\end{array}$ & 0.5556 & 0.990099 & $\mathrm{X} 1$ \\
$\mathbf{2}$ & Handle length (inches) & 15 & 69 & $\mathrm{X} 3$ \\
$\mathbf{3}$ & Handle offset/gap & 1.18 & 1.42 & $\mathrm{X} 27$ \\
$\mathbf{4}$ & Display dimensions (H / W) & 1.4725 & 27 & $\mathrm{X} 31$ \\
$\mathbf{5}$ & $\begin{array}{l}\text { Ice maker Clear plastic to opaque } \\
\text { material ratio }\end{array}$ & 0 & 0.8 & $\mathrm{X} 36$ \\
$\mathbf{6}$ & $\begin{array}{l}\text { Case adjustment levels } \\
\mathbf{7}\end{array}$ & 1 & 5 & $\mathrm{X} 43$ \\
$\mathbf{8}$ & $\begin{array}{l}\text { Sin dimensions material plastic to glass ratio } \\
\mathbf{9}\end{array}$ & 0.01 & 0.15 & $\mathrm{X} 47$ \\
$\mathbf{1 0}$ & $\begin{array}{l}\text { Total fresh food capacity } \\
\text { Usable fresh food capacity }\end{array}$ & 14 & 16.5 & $\mathrm{X} 48$ \\
\hline
\end{tabular}

Results indicate consumer preference for various sensibility words, for example, the Sensibility word "NEW" optimized at $90.6 \%$ (maximum). The optimization model recommends the following: Using Aluminum as finish material, Gloss level to be Low, HMI dispenser material to be Metal, Bin to Colored, and Shelf material Plastic to Glass ratio to be maintained at $1 \%$ Plastic. While the sensibility word robust "FRIENDLY" optimized at $84.9 \%$ (maximum. The optimization model suggests the following: utilizing Plastic accents, No cradle surface, , Display dimension to be Maximum (4 x 6.74 sq inches) and Freezer bin material to be Wire. Sensibility word "ELEGANT" optimized at $90.16 \%$ (maximum). The optimization model suggests the following: Plastic as material, Handle style to be Tapered, Gloss level to High, Button material to be of Metal, Ice maker Clear, Plastic to opaque ratio to be 0.8 , Shelf to have Partial Extension.

Table 5 illustrates the ranking of each refrigerator model according to overall participant's sensibility ratings. We notice that within the low price group GE (GEGSH25JFX) then Kenmore (51014) performed the best. Among the Mid-price group Samsung (RS261) then GE (GSHF6KGZBB) performed the best, while for the high price group GE (PSHS6YGZ) then Samsung RS267TD performed the best, all refrigerator model ranking is summarized in Table 9 below. Next two sections provides explanation for important design variables and how it contribute to each refrigerator overall customer sensibility standing.

According to Refrigerator Pro (http://www.refrigeratorpro.com)., consumers indicate favorite features and certainly could be considered the more innovative and memorable features of all of the different Refrigerators: Customizable Storage: Customers like the flexibility and to easily maneuver the storage, dividers in the drawer to adjust to whatever food items they need. Counter Height Drawers: In some models, the top drawer is counter level allowing easy access to snack foods or common use items. This is especially handy if they have young children as they can provide them easily accessible snacks throughout the day. 
Table 5. Refrigerator Model Rank Per Price Group

\begin{tabular}{|lllll|}
\hline Price Range & Brand & Model Number & $\begin{array}{l}\text { Sensibility } \\
\text { Rank }\end{array}$ & $\begin{array}{l}\text { Best in its Price } \\
\text { Group }\end{array}$ \\
\hline Low price cell & Kenmore & Kenmore 51014 & 10 & $2^{\text {nd: }}$ Kenmore \\
\hline Model B & Whirlpool & WP ED5KVEXV & 11 & \\
Model C & GE & GEGSH25JFX & 9 & l $^{\text {st: GE }}$ \\
Model D & Frigidaire & Frigidaire LFUS2613LP & 12 & \\
\hline Model F & & & & \\
\hline
\end{tabular}

\begin{tabular}{|lllll|}
\hline Mid price cell & & & \\
Model G & GE & GE GSHF6KGZBB & 6 & $2^{\text {nd: }}$ GE \\
Model H & LG & LG LSC27914SB & 8 & \\
Model J & Whirlpool & WP GSF26C5EXB & 7 & \\
Model K & Samsung & Samsung RS261 & $\mathbf{5}$ & 1 $^{\text {st: }}$ Samsung \\
\hline
\end{tabular}

\section{Conclusions}

It is the researcher's conclusion that the customers' psychological perception is greatly influenced by material type and the handle style of the refrigerators. It is recommended that whenever conflicting optimization directional need arise, it is better to look at the coefficient of determinations for the competing sensibility words along with their relative normalized weights from consumers' rating and accordingly assign weights to the words for consideration purpose. Based on the analysis conducted, researchers found that sensibility words most customers do care about when making buying decisions are more accurate to focus on. Since sometimes "mathematically" and "statistically" sound design may have less weight in the eyes of customers purchasing logic and perception. It is recommended that future study design elements consider different levels in different samples to be considered for this kind of study as it provides more promising relationship (if exists) than in the case where one or two levels in the sample considered.

\section{References}

1. Kwon, K.S.: Human sensibility ergonomics in product design. International Journal of Cognitive Ergonomics 3(1), 51-62 (1999)

2. Galí, J.M.: The Functions of the Brand in the Choice Process. In: Bloemer, J., Lemmink, J., Kasper, H. (eds.) Proceedings of the 23rd EMAC Conference, pp. 1281-1284. European Marketing Academy (1994)

3. Galí, J.M., Coenders, G.: Conceptualising and Measuring Brand Functions. Papers ESADE 146, 1-31 (1996)

4. Kapferer, J.N., Laurent, G.: La Sensibilité aux Marques. Fondation Jours de France (1983)

5. Laurent, G., Kapferer, N.: Measuring Consumer Involvement Profiles. Journal of Marketing Research 22, 41-53 (1985) 